\title{
Announcements
}

\section{CALL FOR PAPERS: ADVANCES IN ASSESSMENT AND TREATMENT OF FORENSIC POPULATIONS}

Law and Human Behavior invites manuscript submissions for a special issue focusing on recent advances in assessment and treatment of forensic populations. We are particularly interested in empirical studies and rigorous scholarly reviews addressing either: (1) clinical assessment of forensic issues such as criminal competencies, criminal responsibility, violence risk, mental/emotional damages, child custody, guardianship, etc.;(2) treatment or intervention for forensic-specific issues, such as restoration of competency, reducing violence risk, reducing of criminal recidivism, treatment of victims of crime, treating offender populations, etc. or (3) systems issues related to the assessment and management of forensic mental health populations. Topics relevant to adult and juvenile populations are welcome. A central theme of the issue will be explication of how knowledge, practice, or technology in these fields have been advancing and improving, so all manuscripts should elucidate the implications and importance of the findings for practice and/or policy.

Guest editors for this issue are Randy Borum of Duke University Medical Center and Randy Otto of the Florida Mental Health Institute at the University of South Florida. Four copies of manuscripts, prepared for anonymous review, should be sent to:

\author{
Randy Borum \\ Duke University Medical Center \\ Box 3071 \\ Durham, NC 27710 \\ E-mail:rborum@psych.mc.duke.edu
}

To be considered for this special issue, manuscripts must be postmarked no later than November 1, 1998. 